$\mathbb{T}$ periodica polytechnica

\author{
Social and Management Sciences \\ $21 / 1(2013) 27 \quad 38$ \\ doi: $10.3311 /$ PPso. 2154 \\ http://periodicapolytechnica.org/so \\ Creative Commons Attribution (1)
}

RESEARCH ARTICLE

\section{Social Challenges: Social Innovation through Social Responsibility}

\author{
Piroska Harazin / Kálmán Kósi
}

Received 2013-01-10

\begin{abstract}
There are several methods, which can help organizations evaluate and follow up organizational performance. However, beyond traditional performance evaluation there are new aspects that should be involved into the process of evaluation. According to the authors, these aspects are challenges and influence the long-term competitiveness of organizations. This paper concentrates on answers for social challenges and examines the concept and relationship of social innovation and corporate social responsibility. Social innovation is a real challenge today because innovation is a cornerstone of Europe 2020 Strategy. Business organizations also have a role, interest and responsibility in social innovation, because social innovation can and must come from all sectors. It can be stated that business organizations can engage in social innovation through corporate social responsibility. However, there is a question: are business organizations able to be drivers in social innovation through their social responsibility especially with the help of the most current and practical tool of corporate social responsibility, the ISO 26000 standard.
\end{abstract}

\section{Keywords}

Social Innovation · Corporate Social Responsibility · International Standard ISO 26000 - Guidance on social responsibility · Social Challenge

\section{Acknowledgement}

This work is connected to the scientific program of the "Development of quality-oriented and harmonized $R+D+I$ strategy and functional model at BME" project. This project is supported by the New Széchenyi Plan (Project ID: TÁMOP-4.2.1/B09/1/KMR-2010-0002).

\section{Piroska Harazin}

Department of Environmental Economics, Budapest University of Technology and Economics, Magyar Tudósok krt. 2., Budapest, H-1117, Hungary e-mail: harazin@eik.bme.hu

\section{Kálmán Kósi}

Department of Environmental Economics, Budapest University of Technology and Economics, Magyar Tudósok krt. 2., Budapest, H-1117, Hungary e-mail: kosik@eik.bme.hu

\section{Introduction}

\subsection{System based approach}

There are several methods that can help organizations evaluate and follow up organizational performance. However, beyond traditional performance evaluation there are new aspects which should be involved into the process of evaluation. This fact is not to be contested, because in level of European Commission there are also commitments in connection with measuring progress in a changing world. Communication in 2009 from the Commission of the European Communities to the Council and the European Parliament in the topic of GDP and beyond GDP (measuring progress in a changing world) calls the attention for new, additional aspects beyond traditional evaluation [6]. Like a common fact in these commitments, the Commission suggests complementing traditional evaluating with environmental and social aspects.

The need for evaluation of these new aspects can be interpreted and can be relevant in all levels of the economy, that is why method of environmental performance evaluation has became evolved in organizational - micro - level (Today environmental performance evaluation has established methodology.). However, beyond environmental aspects, organizations meet with additional new challenges, which influence the longterm competitiveness of organizations. According to the authors, organizations' relation to the intellectual capital and society, or integrated approach of the pillars of sustainable development is defined like these new challenges.

However, there is a question how the methodology and tools of environmental performance evaluation can correspond to these new challenges, and how these tools can be used in fields which are not only about environmental aspects. This paper is one step in the system which examines how different aspects can be integrated into already known, used methods of performance evaluation. The aim of this system is enforcing commitments of Commission in connection with measuring progress in a changing world on micro level.

This paper concentrates on answers for social challenges and examines the concept and relationship of social innovation and corporate social responsibility. This paper can be a base for 
a posterior work which tries finding how realization of aims of social innovation and corporate social responsibility can be measured, and how the methodology and tools of environmental performance evaluation can be used in case of these aspects, challenges.

The aim of this paper is the introduction of social innovation and an exact tool of corporate social innovation, like challenges, new aspects, which should be measured and evaluated in a changing world. An additional aim is the representation of the actuality, importance and relationship of these challenges.

\subsection{Background and actuality of the topic}

Core subjects of social innovation and corporate social innovation today are really important fields for business organizations and also for higher decision-maker levels. The examination of these core subjects is justified, if connecting viewpoints of the European Union are taken into account.

Corporate social responsibility plays a big role in the life of business organizations today and this is emphasised by the definition process of the Commission. According to the European Commission - in 2001 -, most definitions of corporate social responsibility describe it as a concept whereby companies integrate social and environmental concerns in their business operations and in their interaction with their stakeholders on a voluntary basis [5]. This was a definition of the Commission, but in October 2011 the European Commission published a new policy on corporate social responsibility, with a new definition of CSR. CSR new policy on corporate social responsibilityas "the responsibility of enterprises for their impacts on society" in this new policy [8, p.6], or in other words this policy states that to fully meet their social responsibility, enterprises "should have in place a process to integrate social, environmental, ethical and human rights concerns into their business operations and core strategy in close collaboration with their stakeholders" [8, p. 6], [10]. What is really important in this new definition is that the word of voluntary is missing. It can emphasise the importance of CSR, because in 2011 it is not a voluntary option, but rather an expectation.

Beyond the importance of changes in the definition of the Commission, additional ways also have to be involved and discussed, which represent characters beyond CSR. That is why there is a concept, which can be a deeper and closer answer which results in a better level of social efficiency for questions of responsibility than existing methods of CSR. This concept is that of social innovation, which can give real answers for real questions, challenges.

Social innovations are new ideas, institutions, or ways of working that meet social needs more effectively than existing approaches. In our days across the world, millions of people are creating better ways to answer the most challenging social problems, for example climate change, chronic disease, social exclusion, and material poverty [25].

The topic of social innovation is really actual and important in the level of European Union, especially since innovation is cornerstone of Europe 2020 Strategy for growth and jobs. President Barroso in 2011 mentioned that Europe has a long and strong tradition of social innovation however the concept is not yet fully accepted in the political debate and raised the attention that today the strong European tradition of social innovation is more needed than ever. According to the results of the 'Launch of Social Innovation Europe Initiative' in 2011, social innovation is a theme that runs through almost all the Commission's key initiatives underpinning the Europe 2020 Strategy. The European Union has a considerable role in social innovation and in the creation of tools, because it can add value to processes by facilitating exchange of good practices across national boundaries and supporting social innovations. European Union can be a catalyst of social innovation [2], [9].

There are several questions in connection with the future economy and welfare of the European Union in the Communication from the Commission to the European Parliament, the Council, the European Economic and Social Committee and the Committee of the Regions. The only answer for these questions is innovation, which is at the core of the Europe 2020 Strategy. The "Innovation Union" is one of the seven flagships announced in the Europe 2020 Strategy, which flagships' aim is to improve conditions and access to finance for research and innovation, to ensure that innovative ideas can be turned into products and services that create growth and jobs. According to the Communication, Europe has a strong position in innovation and also starts from strong position, because there are several Member States and regions which are among the most innovative in the world, in addition economy of the European Union is supported by some of the world's most dynamic public services and strong traditions in social innovation [7].

In order to reach innovation aims successfully in the Union, there are fields which should be developed. All actors and all regions should be involved in the innovation cycle, so major companies, small and medium sized organizations, public sector, the social economy and citizens also have to have a role in innovation. The concept of social innovation is mentioned in connection with this field. In the Communication there are several aims in connection with social innovation, which aims to connect social innovation to financial and research fields [7].

Addressing social issues, the Commission has developed several policies, programmes and initiatives that have contributed to empowering citizens and organisations. There two Structural Funds (European Regional Development Fund and European Social Fund) with budgets of -75 billion (approximately $10 \%$ of the EU's total budget) and -201 billion during 2007 and 2013. But there are several other programs (e.g.: Framework Programmes for Research and Technological Development) which have an aim to finance actions of social innovation [25].

Beyond the role of the European Union in social innovation, other actors also should be mentioned. As the Communication detailed above mentioned that all actors and all regions should 
be involved in the innovation cycle, it is necessary to emphasise that social innovation is a 'multi-actor' process. Social innovation can and must come from all sectors and it is also true that successful innovation solves problems by involving more than one sector. The fact that businesses and business organizations have a role and exercise in social innovation can be proved; as there is growing interest amongst corporate players and industry leaders too. The role of businesses is called 'driver' - between other drivers such as government; civil society and citizens -, which means that businesses have to recognize the social sectors' role in the economy and growth of key sectors such as health or for example green industries [25]. The Open Book of Social Innovation mentions that there are also a variety of ways in which businesses can engage in social innovation. Between the varieties there is corporate social responsibility, the hybrid business models that combine business capacities with social goals, corporate not-for-profit management of social provision, or for example the partnerships between social enterprises and corporations [20]. But most of the literature mentions that businesses should be involved in building a more inclusive society, for example through corporate social responsibility.

Concentrating on the role of corporate social responsibility, it is interesting to examine how the CSR policy of organizations can represent the organization in social innovation. This paper concentrates on how the guidance on social responsibility - standard ISO 26000 - which was published in 2010 can ensure the role of drivers for the organization, or is it able to catalyze the innovation mechanism inside of the organization which results win-win relations between the organization and society and/or environment. (ISO 26000 was chosen because this guidance is today the most practical and current assistance on corporate social responsibility and growing number of the adaptation of this standard is expected.)

Using the attitude of the European Union in social innovation it can be a fact that social innovation is today a real challenge, it has an importance because innovation is a cornerstone of Europe 2020 Strategy. It is also should be emphasised again that social innovation is not only a role and exercise of only one sector, social innovation can and must come from all sectors, so business organizations also have a role, interest and responsibility on it. However there is a question: are business organizations able to be drivers in social innovation through their social responsibility, exactly by the help of ISO 26000 standard.

\section{Understanding social innovation}

\subsection{Theoretical approach}

"There are many fields where we see particularly severe innovation deficits, which are also great opportunities for new creative solutions." [19, p.9]. These deficits are gaps between what people need and what they are offered. The answers for these gaps, deficits become social innovations, which are solutions for the interest of society. Of course parallel with social innovation, technological, scientifically innovation also can be mentioned, because the answers require technological, scientifically solutions [19].

Understanding social innovation it is necessary to get to know and interpret the concepts of social innovation and the common characteristics or differences between these concepts, definitions with the help of literature review. Literature review of the authors shows that a book about social innovation in 1983 already was written- exactly about economic point of view of social innovation (Jonathan Gershuny: Social Innovation and the Division of Labour [12]) - however today's databases don't contain too much scientific literature about social innovation (of course voluntary chosen databases were examined without claim of completeness). Although it is important to emphasise the role of the civil sphere in opinion forming, because there are many international and national organizations, associations, foundations (The Young Foundation, Stanford Social Innovation Review, Center for Social Innovation, Kreater Social Innovation Labour (Hungarian one)), which deal with the concept and achievement of social innovation, and publish different statements, articles, guidance.

Geoff Mulgan in one of the studies of the Young Foundation writes that social innovative actions are "innovative activities and services that are motivated by the goal of meeting a social need and that are predominantly developed and diffused through organizations whose primary purposes are social." [19, p.8]. Social innovation is a new idea, which results in goals that produce advantages for society. However, social innovation also means the summary of innovative activities and services, which are motivated by the produced social advantages, and it is developed and diffused through organization whose primary purpose is social [28].

Pol and Ville collected many of the definitions of social innovation, made a comparison between these definitions and finally came up with their own definition. They define many overlapping points in examined definitions; these are the institutional change, social purposes and public good. Finally Pol and Ville also create a definition for social innovation: "Innovation is termed a social innovation if the implied new idea has the potential to improve either the quality or the quantity of life. Examples of innovation that fit nicely with this definition abound: innovations conductive to better education, better environmental quality and longer life expectancy are a few." [22, p.4]

According to Huddart social innovation is a new point of view for complex problems. Social innovations does not just mean the new ideas, but the new ways of seeing, thinking, and working, which reframes a problem and realigns resources to address the problem more effectively [14].

David Bornstein raises questions in his work - which is according to New York Times, a Bible in the field - like what is the practical role of that innovation process, which has an opportunity to change the world. How to Change the World is about different case studies about social entrepreneurs and new ideas, and examining how poverty can be reduced, how health services 
can be extended to the whole world, how right education can be available for children in the world. This work shows a solution that can be unbelievable, but we can change the world with innovation on behalf of society. Bornstein mentions in his work, that the case studies are not about market, sustainability or efficiency, but about people, who have enough talent to make something good on behalf of others, solve problems across boundaries, or across cities, countries or the world. Although there is no exact definition for social innovation in the work, and Bornstein uses the concept of social entrepreneurs, many characteristics, aspects can be found which can strengthen the before mentioned definitions of social innovation. The literature states that social entrepreneurs are entrepreneurs whose activity shows how management and business practices can be transformed to reaching social results. According to Bornstein, social entrepreneur is the concept about people who cannot say no and always search the answers for the problems by the help of their new ideas [3].

Centre for Social Innovation has an emphasised attention to interpret the definition. Social innovation means the answers for different challenges, so try to find solutions by new ideas, for social, cultural, economic and environmental challenges. According to the Centre the social innovation can come from individuals, groups or organizations, and can be placed in for-profit, non-profit or social sector too. In general, there is an increasing tendency when social innovation is achieved in the gap between these three sectors. This interpretation - the gap between the sectors - appears in the work of the Centre, because they generate these gaps, to catalyze and promote social innovation [4].

The main aim of the literature review is to understand the concept of social innovation and also to examine the common, main characteristics. According to the authors these characteristics can be mentioned as common, general specifics, so social innovation: social innovation results (structural, institutional) changes, comes from new ideas, results advantages for society, results the public good and also for environment, so makes steps forward sustainability.

\subsection{Necessity of social innovation}

Understanding social innovation is important to emphasise why this concept is in the centre of European 2020 Strategy, why the concept of social innovation is needed.

A report from 2010 claims that "a new development paradigm is emerging from the connections between economy and culture, touching on the economic, cultural, technological and social aspects of development both on a macro and micro level" [26, p.16], in addition a study from 2012 represents that for development the innovation and social innovation as a part of innovation is crucial [17]. As was it mentioned before the Communication of the Commission in 2010 asks several questions in connection with the future economy and welfare of the European Union. The only answer in the Communication for these questions is innovation, which is a cornerstone of the Europe 2020 Strategy. In the Communication Commission claims that ,at a time of public budget constraints, major demographic changes and increasing global competition, Europe's competitiveness, our capacity to create millions of new jobs to replace those lost in the crisis and, overall, our future standard of living depends on our ability to drive innovation in products, services, business and social processes and models. This is why innovation has been placed at the heart of the Europe 2020 strategy. Innovation is also our best means of successfully tackling major societal challenges, such as climate change, energy and resource scarcity, health and ageing, which are becoming more urgent by the day." [7, p.3]

According to the Open Book of Social Innovation systemic change is the ultimate goal in the process of social innovation. This step usually involves the interaction of many elements and generally involves new frameworks or architectures made up of many smaller innovations. "Social innovations commonly come up against the barriers and hostility of an old order. Pioneers may sidestep these barriers, but the extent to which they can grow will often depend on the creation of new conditions to make the innovations economically viable. These conditions include new technologies, supply chains, institutional forms, skills, and regulatory and fiscal frameworks. Systemic innovation commonly involves changes in the public sector, private sector, grant economy and household sector, usually over long periods of time." [20, p.15]

Advantages and necessity of social innovation is represented by existing examples, which examples have publicity like social innovations. In these examples is common that also have ensured advantages for the organization which created the social innovation and also for the society and/or environment. Winwin relations, situations, like these examples, can strengthen the necessity and importance of social innovation and emphasises the key role of social innovation in economic, social and environment development.

Win-win situations can be recognized already, because social innovation is a business and societal opportunity. The most important sectors for growth in the next decades are linked to the development of human and social capital which can be already proved because in most countries today health already represents a large share of GDP and the social economy in Europe employs 11 million people that is $6 \%$ of the active population of the EU [25].

Europe has a strong potential for social innovation, a potential that should be used even better. Recognise and introduce the yet existing examples for European social innovation is essential, and the aim is to inform about these good-examples, to strengthen social innovation as a whole in Europe. Social Innovation eXchange [23] (SIX was instigated by the Young Foundation,), Euclid Network and Social Innovation Park (SI Park) presented a survey for the European Commission where they examined over one hundred inspiring social innovation stories. A defined jury selected 10 projects, which represent that which are at the moment happening most promising innovations. These 
selected project represent a diversity which was a requirement during the work, these illustrate diversity - both in terms of geography, sector and social challenge. They defined three criteria which can identify a social innovation, and jury had to use these criteria. Main questions of the survey were the next ones: Does it tackle a real social or environmental need costefficiently? Does it have meaning for those who are involved in it, both for those delivering the service/product (the suppliers), and for those receiving it - (the demand)? Does it create new and effective relationships in society [11]? All of the chosen 10 projects have reached the three criteria, so have reached the requirements. (Because of the limit of the compass, only one example can be represented from the 10 projects. Project called The Copenhagen City - Honey Cooperative is an example from Denmark. With an aim of connecting the remaining expert beekeepers with dynamic social projects and committed local businesses and finding elegant ways to involve all the social layers of the city in creating a sustainable urban honey industry, the projected has resulted the safe of Denmark's honey industry; the reignition of consumers interested in traditional high quality Danish honey; and has created employment opportunities; and has resulted sustainable cites with bees [11]).

Represented projects between the case studies of Social Action strengthen that viewpoint which is about the necessity of projects of social innovation which results win-win relations, situations, so can make economic, social and environmental development. During the selection process five criteria were used: social or environmental innovation, outcomes, impact, process and business. In case of all of the case studies, companies' data, related global problem, project processes, project product, project business model is represented and finally the question is asked that is the project a CSI project [24]. These examined aspects can represent the integrated (business, environmental and social challenges) approach of these projects, so can strengthen the liveability of the social innovations' concept in practice, in the business. (Just for example project called LIFELINK comes from Grundfos, which's essential component is a water pump system in developing countries. This system is not just a means for people to get water - it's a growth enabler in the rural communities. Grundfos is creating jobs because they will start companies in the countries where they have operations. Or for example Interface combines the traditions of handicrafts with modern mass industry, and uses traditional natural and sustainable materials, so traditional artisans can be integrated into the global economy [24]).

In the report of Nordic Innovation Centre, 43 cases of social innovation was collected and analyzed, to summarize the experiences from Nordic countries (especially in case of SMEs). For all of the participant organizations, have a positive response to their products, services and projects that are motivated by CSR issues. In the cases persons, like motivating factors, share the ambition to transform society for the better through innovation, while also aim the financial success. Need for a better communi- cation was common in the cases. Grouping the cases the report uses the typology of CSR-driven innovation business ventures from Hockerts, which defines thee categories of business organizations according to the orientation. Business where profit is a goal, and social impact is as a means, is called 'The Profit from Principles Business'. Where profit and social impact are also goals, it is called 'The Social Purpose Business' and where social impact is a goal and profit is as a means, it is called 'The Missionary Business'. The results of this grouping showed that different behaviours can be defined for organizations according to how implement business and social aspects together, however the cases underlined the importance of making CSR-driven innovation central to the business's strategy [1].

\section{Relation of social innovation and standard of social responsibility}

As was it emphasised before, social innovation is not only a role and exercise for only one sector, social innovation can and must come from all sectors, so business organizations also have a role, interest and responsibility on it. Most of the literatures mention that business should be involved in building more inclusive societies, for example through corporate social responsibility. However there is a question: are business organizations able to be drivers in social innovation through their social responsibility, exactly by the help of ISO 26000 standard.

\subsection{International Standard ISO 26000}

There was a claim for an international standard in connection with corporate social responsibility in 2001. Reaching this claim the process started with commission works, multistakeholder conferences and stakeholder involvement. In 2005 the working-group was formed, to develop the international standard, which introduces the main guidelines of social responsibility and which is useful for non-experts too. 2010 was the publishing date of the standard, which is the ISO 26000:2010(E) Guidance on social responsibility. This standard is useful to all types of organizations in private, public and non-profit sectors, whether large or small, and whether operating in developed or developing countries. It is providing guidance, does not contain requirements but may contain recommendations and it is not a management system standard, so it can't be certified. It defines the principles of social responsibility, the two fundamental practices of social responsibility, the core subjects, the way of integration throughout an organization and examples of voluntary initiatives and tools [15].

According to the model of the ISO 26000 the standard deals with the next fields: terms and definitions of CSR; background and trends of CSR; principles and two fundamental practices of social responsibility, core subjects and integration of CSR. The main chapters of the standard contain the logic of implementation in the guidance, by the steps of implementation and operation. The first step is the scope which is followed by the definition of main terms and definitions, with the interpretation which 
can help understanding social responsibility. In the fourth step there are the principles of social responsibility, which are followed by the chapter called 'Recognizing social responsibility and engaging stakeholders'. Last steps are the deep introduction of the core subjects and the guidance on integration throughout an organization [15].

The seven principles and seven core subjects characterize CSR and also the standard, and mean the theoretical background of the practical implementation of the guidance. Table 1 is about the summary of principles and core subjects of the standard.

The ISO 26000 has a separated chapter to introduce the guidance for implementation of social responsibility throughout an organization. The recognition of social responsibility is the starting point in the implementation process, which is followed by the strategies, action plans, integration and communication, and with the help of these, the stakeholder engagement is continuous. Improvement of the processes is a contribution to sustainable development. There are exact practices in the chapter for the integration, which are the following: raising awareness and building competency, setting the direction of an organization for social responsibility, building social responsibility into the organizations' governance, systems and procedures. Communication, enhancing credibility, reviewing and improving actions are also tasks to do during the integration, implementation. The standard also offers exact, existing, voluntary tools, which can promote the CSR activities [15].

\subsection{ISO 26000 and social innovation}

To analyse the relationship between social innovation and ISO 26000, the main characteristics, criterions of social innovation are the viewpoints in the comparison (which will be also introduced by the help of literature review) and characteristics, core subjects and principles of ISO 26000 are assigned to these viewpoints. Viewpoints and results of the comparisons in each case of viewpoints will be represented.

On the first level, the first viewpoints are innovation deficits' fields, which are in the centre of social innovation (answers for these gaps can become social innovation). Table 2 contains these gaps and characteristics, meanings of them. It is important to mention that in case of these gaps there are many of the existing methods, but these do not work well enough; these are not flexible and unimaginative, past oriented and represent just selected interests [19].

Results of the analysis show that only some of the principles and core subjects of the ISO 26000 have a relation with the gaps; so some of these can be a solution for the gaps, or can promote the social innovation. Results of the analysis show that mostly the core subjects are answers for gaps, especially in those cases where exact chapters contain solutions, answers. There is an order of principles according to the frequency of occurrence in case of viewpoints, gaps: 'ethical behaviour', 'respect for human rights' and 'respect for international norms of behaviour'. There is also an order of core subjects according to the frequency of occurrence in case of viewpoints, gaps: 'human rights', 'labour practices', 'community involvement and development', 'fair operating practices', and in a same place the 'environment' and the 'consumer issue. In the case of this viewpoint the question is that with the use of ISO 26000 - when organization integrate social responsibility throughout an organization - what kind of fields of innovation deficits, gaps can be covered. Results shows that integration of social responsibility according to ISO 26000 can help rising life expectancy, prevent segregation and conflict within the organization, solve the inequity and decrease the incidence of long-term conditions, and the happiness is also can be the result of integration.

On the second level, the second viewpoints are the three key dimensions of most important social innovations, according to Mulgan et al. [19]. The first dimension is that these innovations 'are usually new combinations or hybrids of existing elements, rather than being wholly new in themselves'. Second key dimension is putting the results 'into practice involves cutting across organisational, sectoral and disciplinary boundaries'. And the last, the third dimension means that it 'leaves behind compelling new social relationships between previously separate individuals and groups which matter greatly to the people involved, contribute to the diffusion and embedding of the innovation, and fuel a cumulative dynamic whereby each innovation opens up the possibility of further innovations' [19]. The main question in this analysis is that how does the principles and core subjects influence these dimensions. As a result, there is a relation between the first dimension - innovations "are usually new combinations or hybrids of existing elements, rather than being wholly new in themselves" - and all of the principles and core subjects. In the standard [15] there are mentioned, exact voluntary initiatives/tools, which can be used during the implementation of guidance. There are 75 initiatives/tools in the annex of the standard, and there is also an examination of the relation between of these initiatives/tools and core subjects. Counting the linking points in the examination of the standard, in the first place there is the core subject of 'environment' (there is a relation with 57 initiatives/tools from the 75). Second one is the core subject of 'labour practices' and the third one is core subject of 'human rights'. Of course there are exact references for example Declaration of Human Rights or different ISO standards in the text of the standard too. It is hard to interpret the second dimension in this case, because preferably practical parts of the standards have a relation with this dimension. The third dimension again has a relation with all of the principles and core subjects - however the principle of 'respect for stakeholder interests' can be emphasised. This relationship can be confirmed because there is a new approach in connection with stakeholders in the standard. Previous work of authors is about the relationship between stakeholder conceptions and the standard, which work resulted that in the standard stakeholders are made out from society, and organization has a more specific relationship with these emphasised stakeholders, than with the 'rest' of so- 
Tab. 1. Principles and core subjects of ISO 26000 (own work according to [15]

1 Accountability (Acc): this principle means that the organization should be accountable for its impacts on society, the economy and the environment, which impacts come from decisions and activities of the organization. The organization also should be responsible for different controls, reviews. There are advantages for the organization and for society too by the achievement of this principle. This principle also should be extended for activities which can prevent repetition of unintended and unforeseen negative impacts.

2 Transparency (Trans): this principle means that the organization should be transparent in its decisions and activities that impact on society and the environment. The transparency doesn't mean the full publicity of all of the information, however in some fields information should be available. Some of these information: purpose, nature and location of activities; manner of decision making, implementation and review; performance which is in connection with social responsibility; decisions and activities which has an impact on society, the economy and the environment, stakeholders and manner of identific ation, selection and engagement of them.

3 Ethical behaviour (Eth): the organization should be ethical, which is based on honesty, equity and integrity. This ethical behaviour includes the concern for people, animals and the environment, and also there is a commitment to address the impacts of activities and decision on stakeholders' interests. Without claim of completeness there are some aspects which can promote the ethical behaviour: identification and state of organizational principles; improvement of the governances' structure to promote the ethical behaviour during the decision making and in the interaction with stakeholders.

4 Respect for stakeholder interests (RfSHI): the organization should respect, consider and respond to the stakeholders' interests. It is important to identify the stakeholders; and also to know the interests and the legal obligations; to recognize the stakeholders whose have an important role; to know the relation between the interests and society and sustainable development.

5 Respect for the rule of law (RfRoL): the organization should accept the mandatory rules, laws. The organizations should comply with legal requirements; ensure that relationships also comply with these requirements; should be continuous informed about legal requirements; periodically should review the compliance.

6 Respect for international norms of behaviour (RfINorm): parallel with the respect of rule of law, organization should comply with international norms of behaviour. There many exact situations in the standard for interpretation of this principle, for example: the organization should avoid the relationship with an organization which is not consistent with international norms of behaviour or organization should comply with minimum level of international norms of behaviour when the law or its implementation does not provide adequate environmental or social safeguards.

7 Respect for human rights (RfHR): the organization should respect human rights and should recognize the importance and universality of this. This principle means: respect; respect of universality; to change situations where someone's rights are damaged while others have advantages from this.
1 Organizational governance (OG): organizational governance should take on the responsibility of impacts on decision and activities; and also should take on the implementation of principles of social responsibility into the process of decision making and the implementation. Organizational governance has a role to integrate the responsibility into the organizational culture and also to motive the employees for practical operation of this responsibility.

2 Human rights: human rights are inherent, inalienable, universal and interdependent, so the organization should respect these.

3 Labour practices: include all the policies and practices which have a relation with the achieved work. These practices should be extended for all employees; and for partners. Like a principle in this core subject it is really important that employees are not just factors of production, however they have rights for freely chosen work, and just and favourable conditions of work.

4 Environment: organization has impact on the environment, but not only just at the location. Main principles of this core subject: environmental responsibility, precautionary approach, environmental risk management, polluter pays.

5 Fair operating practices: organization should be ethical with other organizations, whose are not only the contracted partners. There should be a strong cooperation with government agencies, partners, suppliers, contractors, consumers, customers, competitors and associations.

6 Consumer issue: responsibility for consumers, customers. Principles are in case of this core subject: safety, being informed, making choices, being heard, redress, education, healthy environment.

7 Community involvement and development: this core subject means the promotion of public good, and strengthening the civil society. Organization should be the part of the community, and should recognize the opportunities of common, cooperative works. 
Tab. 2. Innovation deficits, GAPs according to Mulgan et al. (own work according to [19|)

\begin{tabular}{|c|c|}
\hline Fields of Innovation Deficits, Gaps 19. & Characteristics \\
\hline Rising life expectancy & $\begin{array}{l}\text { New ways of organising pensions, care and mutual support. } \\
\text { Climate change - which requires new solutions. } \\
\text { Technology also has a role to play - it is necessary in the implementation of changes. }\end{array}$ \\
\hline Growing diversity of countries and cities & $\begin{array}{l}\text { Prevention of segregation and conflicts } \\
\text { Innovative ways of organising schooling; language courses; housing. }\end{array}$ \\
\hline Stark inequalities & $\begin{array}{l}\text { Inequality is presented in every community, social structure. } \\
\text { The inequality results different other social ills, ranging from violence to mental illness. }\end{array}$ \\
\hline Rising incidence of long-term conditions & $\begin{array}{l}\text { There is a need for new social solutions, especially in field of health services, because of the growing } \\
\text { number of different long-run illnesses, like the depression, diabetes, cancers and heart diseases. }\end{array}$ \\
\hline Behaviour problems of affluence & $\begin{array}{l}\text { Because of well-being there are defined different behavioural problems, like the obesity, bad diets, as } \\
\text { well as addictions to alcohol, drugs, gambling. }\end{array}$ \\
\hline Difficult transition to adulthood & $\begin{array}{l}\text { There is a need of solution which helps teenagers starting the way of stable careers, relationships and } \\
\text { lifestyles. }\end{array}$ \\
\hline Happiness & $\begin{array}{l}\text { There are mismatches between rising value of GDP, stagnant value of well-being and decreasing } \\
\text { values of real welfare. }\end{array}$ \\
\hline
\end{tabular}

ciety - there is a separated figure in the standard to interpret this relationship. According to this examination, authors previously strengthen and claimed that in the standard in the concept of social responsibility, word of 'social' can be changed to 'stakeholder'. So the standard is about stakeholder responsibility [16]. In case of this second dimension also there is an order of core subjects according to the frequency of occurrence (using the examination of the standard too): 'environment', 'labour practices', 'human rights', 'community involvement and development', 'fair operating practices', 'consumer issue' and 'organizational governance'. From the principles, the 'respect for stakeholders' can be emphasised. But what is the relation between dimensions and the implementation of ISO 26000? In case of first dimension it is true that according to the guidance of the standard, the CSR activities integrate different, existing incentives/tools - for example GRI's reporting framework helps preparing CSR Statement, or different ISO standards can help achieving core subjects.

But not only the mentioned tools and incentives can strengthen the present of this dimension. Different other existing concepts can help in the achievement of CSR too. For example Diófási and Valkó mention the role of green procurement, which is an obvious tool, because it is one the most active and most demonstrative ways of environmental protection and also creates positive public judgment and in connection with CSR or simply environmental awareness it worth taking actions for environmental protection [27].

The second dimension is interpretable in case of this main question, because social responsibility should be integrated into all functions and into all corporate levels. It can be achieved by the competence building and commitment of organizational governance. In case of the third dimension, the relationship with society also can be interpreted with the stakeholder approach of the standard - emphasising stakeholders, whose are make out from society.

The third levels are the three lens, which can help understanding social innovation and with the adaption one of these lenses can help understanding how changes happen. The first lens is the individuals', who had done something to change the world. These individuals have had an idea and achieved it in a smaller community. For example in the 18th century, Robert Owen stopped employing children under ten or for example Octavia Hill created liveable city. However there are many individuals from all over the world, who has tried to do against the odds and their activities resulted radical changes. The movements mean the second lens, which can involve million of people and have dozens of intellectual and organizational leaders. These movements are different from individuals, because these based on many of sources, mean a complexity and represent different, huge range of ideas, sources. For example environmentalism has spawned a huge range of social innovation from urban recycling to community owned wind farms. These movements are successful, because these build on co-operation. Organizations are the third lens. Innovation can came from new organizations, but older ones also can renew, and these can get an opportunity for new things. Old organizations also have to concentrate on the future and on continuous innovation. So the responsibility for future generations is in this lens [18], [19]. Thirdly the lens of social innovation can be examined, however in this case it is again difficult to make difference between the importance of principles and core subjects. The first lens, the role of individuals is in the whole standard, in spite of that in the standard activities and exercises have a reference for organization. However individuals compose the organization, individuals also have to deal with activities, exercises included in the standard. Role of 'organizational governance' can be emphasised from core sub- 
jects, because leaders with different authorities have a bit bigger role, a power to change the world. There is no direct relation between the standard and the second dimension, which are the movements. But with the third lens again all of the principles and core subjects have a relationship, because guidance of the standard involves the whole organization into the processes. From the core subjects, 'community involvement and development' can be emphasised, because separated chapter deals with social investment - when organizations invest their resources in initiatives and programmes aimed at improving social aspects of community life. Examining the parts of ISO 26000 which are in connection with implementation and operation, level of the ISO 26000 standard, like guidance, builds a responsible organization, which result can be paired to the third lens. It is able to renew the organization by giving guidance in easy and applicable way, and help achieving the theory of social responsibility in practice.

It is important to examine which are the background conditions which promote the happening of social innovation. So these are the fourth level. In general social innovation is likely to happen if these right background conditions are present. These are this background conditions:

- For social movements - basic legal protections and status, open media and the web.

- In business - it can be leaded by the competition, opened culture, available capital

- In politics and government - competing partners, think tanks; innovation founds, contestable markets and plentiful pilots.

- In social organizations - practitioner networks, allies in politics, strong civic organizations, progressive foundations and philanthropists.

- Global links - making easier to share the new ideas [19].

Like a fourth comparison authors examine that how CSR standard correlates with background conditions of social innovation. As a result, there is an order of the appearing principles according to the frequency of occurrence in case of background conditions: in the first place the 'respect for rule of laws' and 'respect for international norms of behaviour', other principles in the second place. There are appearing core subjects in an order according to the frequency of occurrence in case of background conditions: 'community involvement and development' in the first place, other core subjects in the second place. There are also linking points between background conditions of social innovation and implemented CSR activities. Just examining one organization, achieving the guidance of ISO 26000 it is necessary to have basic legal protection and status, open media and the web (1. background conditions), to have competition, opened culture and available capital (2. background conditions); to have commitment of organizational policy and governance (3. background conditions); and to have cooperation with civil organizations (4. background conditions). The global links, like information resources can give new ideas and opportunities (5. background conditions).

In an analysis, during the comparison it is not enough to use only 'positive' viewpoints, so it is important to examine the difficulties and barriers too. So the fifth level examines the barriers in connection with the achievement of social innovation. These barriers are:

- Efficiency - people generally wait for advantages in a short run, which in general do not exist at the beginning. Sometimes the impatience is a barrier in the new, good ideas - this is called 'innovators dilemma'.

- Peoples' interest - risk of change sometimes compared to the benefits.

- Minds - every social system comes to be solidified within peoples' mind in the form of assumptions, values and norms.

- Relationships - because relationship between people is stronger than formal relations and these can strengthen the changes, but also can fail the radical ones [19].

As the conditions, the barriers are also common in CSR standard and in social innovation. There is a need for time for right integration of social responsibility, so the impatience in this case also can be a barrier. That's why CSR standard concentrated at the beginning on the competency building and awareness raising, or for strengthening commitment of organizational governance. These also can strain of the failures, disadvantages which come from peoples' interests, mind and relationships.

The sixth level is the principles of social innovation, mentioned by Huddart. These principles are guidance to achieve effective work in the field of social innovation [14]. (Huddart uses different existing - generally Canadian - examples of social innovation for the creation of principles. After conclusions making he creates general characteristic, which have became principles.) Relation between principles and ISO 26000 is represented in Table 3 .

Like a summary it can be viewed that the principles and the core subjects have a relation with the main characteristics of social innovation, so these can inspire, promote social innovation. However there are principles and core subjects which have greater importance than others. The 'respect for human rights' has the greatest importance between the principles, but the 'ethical behaviour' and 'respect for international norms of behaviour' are also have great importance. From the core subjects 'human rights', and 'community involvement and development' have the greatest importance, and these are followed by 'labour practices'. It can be claimed that integrated - according to guidance of ISO 26000 - and achieved social responsibly activities, and also the result of these, can be a social innovation. However a note should be made which is in connection 
Tab. 3. Relation between 12 principles of social innovation and ISO 26000 (own work)

12 principles of social innovation 14$] \quad \begin{aligned} & \text { Suggestions, aspects which are in the ISO } 26000 \text { in connection with } \\ & \text { the given principle of social innovation }\end{aligned}$

1. principle: 'Work at scale requires long time lines and strategic intent.' Strategy definition and planning, competency building and awareness rising there are exact chapters about these, chapters No. 7.4.1. and 7.4.2.

2. principle: 'Strategy is phase and scale dependent.' (Just in time - it is not dependent that in which part of innovation what kind of tool is used.)

3. principle: 'Listen to the system.' (By the help of innovation surprises unfold.)

Step by step logic during integration social responsibility throughout organization - chapter No. 7

There is an information-box in the standard about the benefits of social responsibility for an organization, and the answers which are prepared by the standard for innovation deficits, gaps, are also confirm the achievement of this principle.

4. principle: 'Reflect.' (Is helpful in documenting decisions taken and linking current strategy to larger purpose.)

Chapter No 7.7. deals with the reviewing and developing activities during the integration process.

5. principle: 'Trust is essential.' (It is based on commitment to public Transparency and accountability are principles in the standard. Chapter No. 7.6 good, transparency and accountability.) is about enhancing credibility.

6. principle: 'Learn to work across sectors.' (Inter-sectoral collaboration is rich resource of innovation, for example learn to solve language and cultural differences.)

7. principle: 'Commit to social inclusion.' (Inclusion of vulnerable population)

8. principle: 'Set minimum specification' (... when working at multiple places, and levels, allowing partners to adopt.) Education and competency building is emphasised in chapter 7.4.

9. principle: 'Share information.' (Being opened for new information and relationships: academic and practical co-operation.)

10. principle: 'Work with diverse professionals.' (Complex problems should be solved with complex approach.)

Responsibility and respect for organizations' stakeholders. Chapter No. 5.3. is about stakeholder identification and engagement.

Respect for rule of law, international norms of behaviour are principles in the standard.

Communication in chapter No. 7.5 .

Integrating social responsibility throughout an organization, into all organizational levels and functions.

11. principle: 'Effective use of the media' (Helps communicating and Communication in chapter No. 7.5. formulating.)

12. principle: 'Acknowledge the personal dimension. ('We cannot change any problem unless we accept our own role in it. Humanizing one's adversaries is a key to overcoming conflict and brings us closer to collaboration.)

In the achievement of the principles, core subjects and the integration, the organization is named like a subject. But organization is composed by people, individuals.

with sphere of stakeholders, society. According to the analysis of the authors, with the use of ISO 26000, an organization can reach and achieve the conditions, characteristics, principles of social innovation, but according to the standard instead of society, stakeholders should be emphasised, and in a closer sense employees should be emphasised during integrating social responsibility, in the same word achieving social innovation.

\section{Conclusions}

It can be a fact that social innovation is today a real challenge it has an importance because innovation is a cornerstone of Europe 2020 Strategy. It is also important to mention that business also has a role and responsibility in social innovation, as social innovation can and must come from all sectors. Most of the reviewed literatures mention that business should be involved in social innovation for example through corporate social responsibility, however there is a question: are business organizations able to be drivers in social innovation through their social responsibility, exactly by the help of ISO 26000 standard.
The question was answered by examining the relation between the main theoretical characteristics of social innovation, like levels, viewpoints and principles and core subjects of social responsibility. Conclusion of the examination is that there is a relationship between the principles and core subjects of the ISO 26000 and social innovation, so principles and core subjects, and the ISO 26000 is able to inspire, promote social innovation. However there are principles and core subjects which have greater importance than others. The 'respect for human rights' has the greatest importance between the principles, but the 'ethical behaviour' and 'respect for international norms of behaviour' are also has great importance. Between the core subjects 'human rights', and 'community involvement and development' have the greatest importance, and these are followed by 'labour practices'. At least final conclusion of examination is that the use of ISO 26000 results social innovation by organization, however there is a note that according to the standard instead of society, stakeholders should be emphasised, and in a closer sense employees should be emphasised during integrating 
social responsibility, in the same word during achieving social innovation.

Main conclusion of this paper is that implementation and operation of ISO 26000 promotes the realization of aims of social innovation however several remarks should be mentioned:

1 There is no incentive mechanism which inspires organizations for implement social responsibility actions according to ISO 26000 , so there is no incentive through this tool for realization of social innovation.

2 Potential incentives are not relevant in the case of ISO 26000. There is already no practice that for example use of standard in environmental management system (ISO 14001) is controlled or required in law, however it is a used, existing standard for years; so use of ISO 26000 won't be controlled in law. Regulations' push effect is not relevant in this case. Expectations about this standard from society and suppliers, partners, like pull effect, incentive is also irrelevant in this case because the publicity of this standard is not too high yet (Maybe it thanks to that the standard has been in use only since 2010). This is proved by authors by a help of short primer research which is not representative, but help in the exclusion of pull-effect. In 2012 representatives of different companies (they were asked in a workshop) were asked about ISO 26000. The result of this short research showed that only $37 \%$ of the asked representatives have heard about ISO 26000 and none of the asked companies uses the standard during social responsibility processes. If the companies, representatives haven't heard about this standard, how expectations about this standard from society can be mentioned. However in the world there are some existing examples for the use of ISO 26000 and authors found examples in case of multinational organizations. According to work of Hall and Schmidt there are early implementers of ISO 26000, especially from Netherlands; Denmark; Germany; Canada; China; Japan; South Africa; and generally ISO 26000 during "multistakeholder" consensus processes is used to strengthen stakeholder engagement [13].

3 It is important to mention that ISO 26000 can be a similar role in applications like environmental (ISO 14001) or quality management (ISO 9001) systems have. Use of ISO 26000 can be a requirement of applications, or applications can give opportunity by the pay-off of implementation cost of standard, to implement ISO 26000. Authors claim that this role of ISO 26000 can be a good incentive for the implementation, for use.

4 According to the authors the implementation and operation of the standard promote the continuous improvement for the organization. Realization of core subjects and principles, implementation of new aspects are not short term exercises, so during long period, in long run there are innovation opportunities for organization, for society or for - in a closer sense stakeholders, employees.
5 Business can be a driver in social innovation, if recognizes the social sectors' role in the economy and grow of key sectors such as health or for example green industries. According to the authors the standard can help for organizations to be drivers, because several core subjects and principles can be pared with the before mentioned short definition of drivers.

6 It is important to go back a bit to the literature review, to the definitions of the concept of social innovation, because yet being known the results of the examinations (of the authors), these definitions also can strengthen and confirm the main results of this work. OECD's definition [21] of social innovation concentrates for the relation of individuals and fields of labour (working conditions). This definition can be completed by the ISO 26000, which also deals with employees in different points from ethical behaviour to labour practices and so on. Taking into account the statement of the authors, ISO 26000 instead of society rather deal with stakeholders, in a closer sense with employees. It can be interesting to concentrate on the note of Pol and Ville [22] in connection with the definition of Young Foundation [28], when they discuss the role of profit oriented organizations in social responsibility, in social innovation. It is important to rethink this because the standard also gives guidance for profit oriented organizations, and by the help of the standard, these can reach results, values for society, stakeholders. Bornstein [3] mentions the social entrepreneurs (individuals) whose transform the management and business practices to reaching social results.2. examples in case of multinational organizations. This is the same in ISO 26000, because it is guidance that how can social responsibility be integrated throughout the whole organization, into different levels, different functions to reaching results, values for society, stakeholders.

7 As in theory of performance evaluation the strategy's break down is essential, in the case of global problem solving also have to break down the activities. However all over the world millions of people are creating better ways to tackle some of the most challenging social problems of our times, it is valuable making these processes step by step. Social innovation can be achieved inside of the organization, by the help of ISO 26000. It can be a first step for organization reaching global challenges at final. Many of concepts can strengthen this step. For example strategic human resource management (inside the organization) also promote the organization to understand the environmental and social challenges which at finally will promote the competitiveness and the corporate strategy.

8 There is a chapter in the standard in connection with performance evaluation, however exact method and tool is not mentioned how organization is able to integrate the social aspect into the performance evaluation - only use of indicators is mentioned. So there is no exact solution to enforce commitments of Commission in connection with measuring progress in a changing world in micro level. 
Main conclusion of the authors is that ISO 26000 is a tool of corporate social responsibility which promotes the social innovation; however the background, which can inspire the business organization on social responsibility according to ISO 26000, so through social responsibility on social innovation, is incomplete.

\section{References}

1 Als B, CSR-Driven Innovation - Combining design and business in a profitable and sustainable way, Nordic Innovative Centre, 2010, http://nordicinnovation.org/Global/_Publications/ Reports/2010/CSR-DRIVEN\%20INNOVATION\%20-\%20Combining\% 20design\%20and\%20business\%20in\%20a\%20profitable\%20and\% 20sustainable\%20way.pdf lecture at Nordic Innovative Centre.

2 Barroso JMD, Europe leading social innovation, Social Innovation Europe Initiative, 17-03-2011, In:, 2011, http://ec.europa.eu/enterprise/ policies/innovation/files/sie-conference/barroso-speech11-190_en.pdf

3 Bornstein D, How to Change the World, Social Entrepreneurs and the Power of New Ideas, Oxford University Press; New York, 2007.

4 Center for Social Innovation, 2008, http://www. socilainnovation.ca/ about/socialinnovation

5 European Commission, Promoting a European framework for Corporate Social Responsibility, Green Paper; Brussels, 18-07-2001, http://eur-lex.europa.eu/LexUriServ/site/en/com/2001/ com2001_0366en01.pdf. Report No.:COM(2001) 366.

6 European Commission, Beyond GDP; Measuring progress in a changing world, Communication from the Commission to the Council and the European Parliament, http://eur-lex.europa.eu Report No.:COM (2009) 433 final.

7 European Commission, Europe 2020 Flagship Initiative Innovation Union SEC(2010), Communication from the Commission to the European Parliament, the Council, the European Economic and Social Committee and the Committee of the Regions; Brussels, 6-10-2010, http://ec.europa.eu/enterprise/policies/innovation/policy/ innovation-union/communication/iu_en.pdf Report No.:COM (2010) 546 final.

8 European Commission, A renewed EU strategy 2011-14 for Corporate Social Responsibility, Communication from the Commission to the European Parliament, the Council, the European economic and Social Committee and the Committee of the Regions; Brussels, 25-102011, http://ec.europa.eu/enterprise/policies/sustainablebusiness/files/csr/new-csr/act_en.pdf. Report No.:COM (2011) 681 final.

9 Social Innovation Europe Launches in Brussels: the Innovation Union moves forward, Conference Report, http://ec.europa.eu/enterprise/ policies/innovation/files/sie-conference/andor-speech11-189_en.pdf http://ec.europa.eu/enterprise/policies/ innovation/files/sie-conference/conference-report_en.pdf

10 European Commission, Sustainable and Responsible Business. New European Policy, http://www.ec. europa.eu

11 European Commission, Enterprise and Industry, This is European Social Innovation, (Instigated and coordinated by the Social Innovation eXchange (SIX) at the Young Foundation, Euclid Network, and the Social Innovation Park, Bilbao), 2010 December, accessed Enterprise \& Industry online magazine, http://www.youngfoundation.org/publications/ reports/this-european-social-innovation-december-2010

12 Gershuny J, Social Innovation and the Divisionof Labour, Oxford University Press; New York, 1983.

13 Hall P, Schmidt C, ISO 26000 Guidance on Social Responsibility: What it means for your company, MACTEC, http://www.nhbsr.org/uploads/ iso-26000/iso-26000.pdf

14 Huddart S, Patterns, principles, and practices in social innovation, The Philanthropist, 13(3), (2010).

15 2010(E) Guidance on social responsibility, 2010, Standard No.:ISO 26000.

16 Kósi K, Harazin P, Theoretical Stakeholder Approaches in the practice oriented ISO 26000 Standard (Elméleti stakeholder-koncepciók a gyakorlatorientált ISO 26000-es szabványtervezetben), In: Buday-Sántha A, Erdősi F, Horváth G (eds.), Annual 2010, "In Halftime” (Évkönyv 2010. "Félidőben"), 2010.

17 Culture as a factor of economic and social innovation, In: Köster PR, Sanchis RA (eds.), www.uv.es/soste/pdfs/Sostenuto_ENG.pdf This draft 1.0 of the report will be discussed during the Sostenuto Final Conference, to be held on 19-20 January 2012; Cultural Economics Research Unit of the University of Valencia (Econcult), Interuniversity Institute for Local Development (IIDL).

18 Mulgan G, The Process of Social Innovation, Innovations, Spring, (2006).

19 Mulgan G, Tucker s, Ali R, Sanders B, Social Innovation. What is it, why it matters and how it can be accelerated, The Basingstoke Press, The Young Foundation, 2007, http://www . youngfoundation.org

20 Murray R, Caulier-Grice J, Mulgan G, The Open Book of Social Innovation, The Young Foundation, The LAB, Nesta, March, 2010, http://www.nesta.org.uk/library/documents/Social_ Innovator_020310.pdfs

21 OECD LEED, Forum on Social Innovation, http://www.oecd.org/ document $/ 53 / 0,3343$, fr_2649_34459_39263221_1_1_1_1,00.html In: Pol, E., Ville, S.: Social innovation: Buzz word or enduring term? The Journal of Socio-Economics 38, (2009), pp. 878-885.

22 Pol E, Ville S, Social innovation: Buzz word or enduring term?, The Journal of Socio-Economics, 38, (2009).

23 Pulford L, Nordstokka K, Friesen C, Sigaloff C, Moerbeek K, Loon L, Co-creation Guide. Realising Social Innovation together, http://socialinnovationexchange.org/ideas-and-inspiration/ methods-and-tools/articles/co-creation-guide-realisingsocial-innovations Social Innovation eXchange (SIX), Knowledgel and Dialogue Café.

24 CSI. Corporate Social Innovation. Case Studies., (Social Action), FORA, http://www. foranet.dk

25 Social Innovation Europe. Financing Social Impact; Funding social innovation in Europe - mapping the way forward, European Commission, 2012, http://ec.europa.eu/enterprise/policies/innovation/files/ funding-social-innovation_en.pdf

26 UNCTAD, Creative Economy Report 2010. In: Köster, P.R., Sanchis, R.A. (eds): Culture as a factor of economic and social innovation. This draft 1.0 of the report will be discussed during the Sostenuto Final Conference, to be held on 19-20 January 2012. Available at: http://www.uv.es/soste/ pdfs/Sostenuto_ENG.pdf

27 Valkó L, Diófási $\mathbf{O}$, Training methods for purchasing officers to facilitate green procurement in Hungary, 3rd International Symposium on Environmental Management Conference, (Zagreb, Croatia, 2011-10-26-28.), In: Koprivanac N, Kusic H, Bozic L (eds.), 3rd International Symposium on Environmental Management Conference Proceedings: Towards Sustainable Technologies.

28 Young Foundation, Social Innovation: what it is, why it matters, how it can be accelerated, 2007. In: Pol, E., Ville, S.: Social innovation: Buzz word or enduring term? The Journal of Socio-Economics 38, (2009), pp. 878-885. 